\title{
Percepção e Cor: Nota sobre o octaedro das cores em Wittgenstein
}

\author{
João Carlos Salles \\ jcsalles@gmail.com \\ Universidade Federal da Bahia, Salvador, BA, Brasil
}

resumo A percepção envolve muitos enigmas, nem sempre parecendo estar assegurada a unidade entre seu conteúdo e sua forma. Exemplificam tais enigmas as ilusões óticas, 0 célebre problema de Molyneux e também, como aqui nos interessa, o problema da expressão das cores em modelos cromáticos, que expressam incompatibilidades lógicas, mas se referem ao próprio território da experiência com cores e pigmentos. Neste nosso texto, distinguiremos dois usos do Farbenoktaeder por Wittgenstein, registrando a diferença, que julgamos relevante, entre a incompatibilidade ampla e a incompatibilidade restrita entre cores.

palavras-chave Wittgenstein; Modelos cromáticos; 0ctaedro; Incompatibilidade ampla; Incompatibilidade restrita; Gramática.

"Ein rötliches Grün gibt es nicht" ist den Sätzen verwandt, die wir als Axiome in der Mathematik gebrauchen.

(WITTGENSTEIN, MS 133, p. 25r) ${ }^{1}$

A percepção envolve enigmas de diversas ordens. Isso talvez por parecer abrigar, a um só tempo, necessidade e contingência, dispondo-se externa e íntima, no mundo e em nós, como se indefinida sua instalação no reino do ser ou no da aparência. Não por acaso alguns programas de investi- 
gação bastante produtivos da história da filosofia voltaram-se a ela, como enfrentar um solo ou uma neblina, por cuja cifra importaria decidir inclusive a própria unidade da experiência e, com isso, a possibilidade de esta ser conhecida.

Interessa-nos chamar a atenção para a ideia de que, formulados segundo interesses e matrizes teóricos distintos, muitos dos problemas suscitados pela percepção têm como pano de fundo o problema mais amplo da unidade da experiência, de modo que, assim compreendidos, podem fazer dialogar contribuições filosóficas relativamente afastadas. Por exemplo, um programa célebre de investigação da percepção resulta da questão proposta por Molyneux a Locke, qual seja, a de saber se um cego, que aprendera pelo tato a distinguir cubos de esferas, tendo sua vista restaurada por uma arte qualquer, os reconheceria e distinguiria de imediato, antes de tocá-los, e também se saberia, pela simples vista, que estão fora do alcance de suas mãos, caso dispostos a grande distância.

O problema, para cuja solução muitos ensaiaram até experimentos científicos, envolve questões filosóficas importantes, como a de saber se os sentidos estão unificados por estruturas prévias, cujas medidas compartilhariam, ou se, ao contrário, lembrando uma fórmula de Voltaire, são e permanecem três objetos distintos o coche que escuto do meu quarto, o que observo desde minha janela e aquele em que enfim venho a entrar. ${ }^{2}$ Por esse ângulo, podemos ver bem como o problema de Molyneux em muito se aproxima de questões que desafiaram a psicologia da Gestalt ou outros teóricos que trabalharam com ilusões óticas. Nesse sentido, a célebre imagem de Müller-Lyer (que, desde 1889, desafia cientistas e filósofos, fenomenólogos, psicólogos ou filósofos analíticos) interroga exatamente a problemática unidade entre a verdade do visto (a de serem diferentes as duas setas) e a verdade do medido, ou seja, a verdade de, para o tato ou por recurso a uma régua, as setas terem o mesmo tamanho.

Por conta de desafios de fundo como esses, queremos crer, o problema de Molyneux, o inteiro programa da Gestalt e outros desafios da percepção (em especial, os que envolvem cores), continuam a fazer confluir contribuições convergentes ou opostas da filosofia e da psicologia em torno da forma mesma do mundo e da possibilidade do conhecimento. Nessa linhagem de problemas, pelos quais o dado aos sentidos parece solicitar ou desafiar estruturas prévias do mundo ou do conheci- 
mento, temos aqueles relativos às cores. Nesse campo, uma das respostas importantes e das mais radicais ao problema da unidade da experiência, inclusive perceptiva, é a fornecida por Wittgenstein. No caso, queremos crer que, tendo naturezas distintas suas respostas ao problema da expressão dos fenômenos, sua perspectiva comum consiste em afirmar um modo especificamente linguístico de estruturação da experiência que, também no campo dos fenômenos, se dispõe a uma expressão e, enfim, pode ser dita. Esse traço comum faz remeter o problema inteiro da percepção a uma análise gramatical, às regras lógico-gramaticais de expressão da cor o que confere singular interesse aos modelos cromáticos.

Um vezo wittgensteiniano característico consiste em afastar soluções extralinguísticas, como as que fariam depender a solução de paradoxos de um exame da natureza da cor. Apesar desse traço comum a sua obra, julgamos haver dois modos distintos de tratamento da cor, correspondentes a duas formas de compreensão dos modelos cromáticos. Um modelo cromático pode servir simplesmente para localizar uma cor por confronto a outras, marcando relações de incompatibilidade ampla entre todas elas. Contudo, pode servir também, de modo mais específico, para marcar diferenças gramaticais irredutíveis a substratos empíricos, estabelecendo relações que preferimos enunciar como sendo de incompatibilidade restrita, relações que envolvem muita vez uma escolha e diferenciação pragmática entre cores.

O problema da exclusão das cores, típico da incompatibilidade ampla, está na origem do abandono de teses essenciais do Tractatus. "Isto é verde e isto é vermelho", referindo-se essas proposições em conjunção a um mesmo fragmento monocromático, não parece ter a forma de uma contradição, embora comporte uma clara incompatibilidade. Por princípio, o Wittgenstein do Tractatus espera ver reconduzida tal expressão, mediante análise verifuncional, à forma estrita de uma contradição, como se, por exemplo, "ser verde" contivesse, às ocultas, a afirmação de "não ser vermelho, azul, amarelo, verde mais escuro, etc.”. Conhecemos todos, o fracasso de uma análise nesses termos ou em assemelhados, cujo resulta- 
do é a proposição, em "Some Remarks on Logical Form”, de um abandono do princípio de independência de proposições assim elementares: ${ }^{3}$ proposições sobre cores que (em função de incompatibilidades no campo da expressão de gradações, ineludíveis, mas inexpressáveis de modo verifuncional) seriam elementares e, todavia, incompatíveis entre si.

Se arriscarmos um modelo cromático propício à expressão de tais relações entre cores, poderíamos lembrar, em primeiro lugar, de algo semelhante ao modelo de Schopenhauer, sendo a cor uma espécie de construção transcendental, instalada, contudo, na retina, na qual se traduziria a cor-sombra como uma divisão, uma fração, entre o branco e o preto. Aparentemente, esse primeiro modelo, uma simples reta limitada pelo '0' e o ' 1 ', poderia expressar satisfatoriamente a exclusão de uma cor em relação às demais, uma vez que ser um ponto excluiria a possibilidade de ser qualquer outro. Esse modelo, porém, bastante datado, teria pouca ou nenhuma serventia científica, estaria comprometido com uma visão insuficiente da cor, pois nele croma, matiz e luminosidade são, em suma, o mesmo.

Com efeito, desde Runge, passando por Wundt, Ebbinghaus e mesmo por Ostwald (para Wittgenstein, o arquicharlatão), a preferência passou a recair sobre modelos tridimensionais, pelos quais as múltiplas dimensões poderiam encontrar suas coordenadas. Assim, em função dos interesses da pintura, das tapeçarias, da expressão de relações de harmonia, etc., os modelos foram sendo torcidos e distorcidos, avançando de pirâmides a romboedros, com inclinações de seu eixo ou eixos, como se pudessem registrar, em um mapa mundi, as combinações e relações efetivas da cor, os jogos possíveis de raios luminosos ou pigmentos, a combinatória (harmônica ou não) do visível. Poucos modelos enfatizam aspectos fenomenológicos (no caso, interdições de essências), como o farão Hering e Runge, por oposição a Ostwald e Helmholtz.

Wittgenstein, também, uma primeira vez em 06 de fevereiro de 1929, recorre ao octaedro das cores - modelo que já lhe serve então para ensinar diferenças, mas em um sentido preciso. $\mathrm{O}$ octaedro localiza a cor, expressando uma espécie de interdição múltipla, mas não da forma que o fará ao tempo das Anotações sobre as Cores ou mesmo logo em seguida, no período intermediário. Nessa primeira referência ao octaedro, afirma-se antes que cada ponto de sua superficie representa uma cor, mostrando-se, 
por exemplo, um violeta claro (weißliches Blaurot) mais próximo do vermelho (Rot) que do azul (Blau). Trata-se então de uma distância espacial, passível de expressão por um número, de sorte que teriam a mesma multiplicidade lógica o modelo, o sistema de números racionais e o espaço visual a ser representado. O fundamental então é essa superfície expressar uma relação expansível, da mesma natureza lógica do que pretende representar. ${ }^{4}$

\section{3.}

Nenhuma figura, porém, antecipa sozinha seu significado ou controla seu emprego, com independência desse mesmo uso e, no caso de uma representação, de seu contexto teórico. Se o modelo de Schopenhauer dificulta o enunciado de certas relações enquanto enfatiza outras, bem podemos imaginar regras de interpretação que o tornariam capaz de expressar incompatibilidades diversas da incompatibilidade ampla. Também o octaedro não significa por si uma revolução, não sendo possível ver, digamos, na antecipação da esfera de Runge a análise wittgensteiniana da gramática das cores, conquanto sejam impressionantes suas imagens para exprimir incompatibilidades. Wittgenstein, por isso mesmo, cita Runge: "Caso alguém deseje imaginar um laranja azulado, um verde avermelhado, ou um violeta amarelado, sentir-se-ia como em um vento norte vindo do sudoeste... branco e preto são ambos não transparentes ou corpóreos... água branca e pura é tão inimaginável quanto o leite cristalino". 5

O octaedro, entretanto, é certamente mais dúctil que a simples reta, e pode oferecer bem mais que a expressão de incompatibilidades amplas, não precisando restringir-se ao registro exato ou o mais aproximado das propriedades externas da cor: pode ser uma apresentação panorâmica e perspícua de regras gramaticais. Ao explorá-lo posteriormente,Wittgenstein renuncia à exclusiva exploração da incompatibilidade ampla entre instanciações de uma mesma dimensão qualitativa, passando a dirigir-se a incompatibilidades restritas e específicas do espaço das cores. E isso já acontece exatamente um ano depois, em 02 de fevereiro de 1930, quando ao espaço das cores já corresponde um espaço gramatical. Será, então, preciso separar os fenômenos psicológicos que o modelo cromático ajuda 
a prever, como o de que uma pós-imagem retiniana vermelha se seguirá a tais e tais circunstâncias (o que é contingente e da alçada da psicologia), das interdições gramaticais que o modelo prescreve e mesmo o estruturam. ${ }^{6}$ Agora, em uma mudança na natureza do modelo e não em sua figura, o octaedro das cores passa a ser simplesmente gramática, "pois afirma que podemos falar de um azul avermelhado, mas não de um verde avermelhado, etc."7

A interdição passa a ser restrita. Com isso, o modelo passa a ensinar diferenças em outro e mais sofisticado sentido. A localização de uma atribuição cromática em um contínuo é doravante apenas um dos aspectos gramaticais do Farbenraum e não pode anular nem traduzir a natureza também gramatical dos demais aspectos. Diferenças são então colhidas no exame do emprego ordinário de expressões para cores, e o octaedro as reflete e faz saltar aos olhos, sendo privilegiado por isso. Finalmente, portanto, fenomenologia é gramática. Por isso mesmo, com esse novo e intenso sentido, Wittgenstein pode preferir a expressão do espaço das cores por meio do octaedro, opondo-se à diluição do duplo cone, menos apto a expressar a assimetria dos pontos excelsos em seu equador. Prefere assim, no equador, o quadrado ao círculo. ${ }^{8}$

\section{4.}

O modelo do octaedro pode configurar a unidade da experiência perceptiva em um sentido mais profundo. Não ajuda simplesmente a prever o resultado de algum experimento, não diz o que provavelmente veremos ou o que deve ser agradável ver, mas antes o limite do que podemos reconhecer como visível. A razão da preferência é gramatical, para marcar a diferença entre ser uma mistura de duas cores (próprio da expressão de pigmentos) e estar entre duas cores (próprio das possibilidades gramaticais). Trata-se de preferir o modelo que deixa ver melhor o aspecto essencial, envolvendo inclusive relações assimétricas e passagens interditadas. ${ }^{9}$

Wittgenstein explora então essa natureza gramatical, através da qual o octaedro passa a cifrar a possibilidade de enunciados significativos sobre a cor, sendo artificio apenas como seria um artificio a geometria eucli- 
diana, que, de resto, também é parte da gramática. Em especial, enuncia uma importante distinção gramatical, cuja relevância um grave erro na edição do TS 209 contribuiu para ocultar, qual seja: falando de cores e não de pigmentos, há ângulos de $45^{\circ}$ significativos e outros não significativos, porque há pontos excelsos a $90^{\circ}$. E essa posição privilegiada não pode ser deslocada, não pode ser reduzida a ângulos de $45^{\circ}$ e assim sucessivamente, chegando no limite a um círculo, em que são privilegiados todos os pontos e, logo, ponto algum. E esta é uma típica observação fenomenológico-gramatical. ${ }^{10}$

Com essa questão, decide-se a forma do "equador" do modelo cromático, marca-se a diferença entre as primárias (indescritíveis, linhas divisórias no círculo cromático) ${ }^{11}$ e as cores que por elas podem ser descritas, decidindo-se pela própria natureza gramatical de várias interdições. Com isso, uma assimetria gramatical, sendo constitutiva do nosso sistema cromático, apresenta dessemelhanças anteriores a qualquer consideração hipotética, cumprindo tarefas próprias de uma "fenomenologia". Assim, essa primeira exploração do espaço das cores no que ele tem de específico, no que se distingue da simples gradação, tem função e resultado precisos. Ela coincide com a identificação entre fenomenologia e gramática e mesmo a perfaz, no que se refere a cores. Não é de estranhar que os modelos sejam então quase equivalentes a uma mineralogia da cor, quando antes nos propiciam sua cifra. Tampouco é surpreendente que venham a recobrir algo como a história natural da cor ou mesmo a própria natureza da cor, pois simplesmente articulam nossa própria capacidade de falar de cores, assim como nossos sistemas numéricos nos tornam possível uma experiência com números e quantidades. ${ }^{12}$

E importa observar que o octaedro não tem sua preferência por colarse melhor a distinções específicas próprias da manipulação de cores, ou por permitir a previsão de resultados ou efeitos cromáticos. Ele é simplesmente uma apresentação sinóptica das regras gramaticais, na qual ser uma cor pura não é uma decantação fisica, mas uma posição no sistema. ${ }^{13} \mathrm{E}$, como apresentação gramatical, com a resistência ao dogmatismo de uma fenomenologia, tampouco pode doravante pretender direitos universais, não sendo certo que as cores, sendo sempre nossas cores, sendo sempre e necessariamente as cores no interior de nosso sistema cromático, sejam universalmente as únicas cores possíveis. É possível então pressentir que a 
negação de uma fenomenologia também comprometerá a filiação de Wittgenstein a um modelo específico do espaço das cores. Por conseguinte, a representação aproximada do espaço das cores pelo octaedro, conquanto continue a preferida, estará cada vez mais longe de ser única. Em todo caso, se fenomenologia é gramática, as proposições gramaticais cifradas no octaedro não sofrem com resultados inesperados de alguma mistura, uma vez que um modelo cromático, quando não empregado hipoteticamente, não serve a algum experimento; ele é empregado para efeito de cálculo ("zu einer Rechnung"). ${ }^{14}$

\section{5.}

As futuras Anotações sobre as Cores não modificam o aspecto já antevisto neste momento do período intermediário, no qual Fenomenologia é Gramática. Entretanto, a construção da interdição incorpora na obra derradeira um componente pragmático que nada tem de adventício, uma vez que nele reside tanto a ligação entre linguagem e mundo, como a quebra com um padrão de modalidades pelo qual necessidade e universalidade coincidiriam. O octaedro, enfim, inspira a organização da experiência perceptiva, continua a prescrever-lhe um campo de possibilidades, mas no interior de certos jogos de linguagem, cujo arco de variações não pretende poder esgotar.

É lição wittgensteiniana bastante conhecida a de que uma figura qualquer nada diz ao certo fora de um contexto. Por isso mesmo, um desenho idêntico pode ocorrer em diversas partes de um livro de física, significando, todavia, diferentemente a cada caso. Se toda representação mostra o que diz, nenhuma diz por si o que mostra. É claro que há representações melhores e piores para nossos propósitos, e algumas, de tão boas ou adequadas, parecem até carregar consigo o próprio contexto, como se guardassem alguma medida unívoca e fossem imunes às intempéries do uso. Sabemos, porém, que, no limite, não pode ser assim, e nenhuma representação diz sozinha quais interdições comporta, as que lhe seriam próprias ou constitutivas.

É natural que isso também valha para as representações gramaticais panorâmicas, em especial, para os modelos cromáticos utilizados por 
Wittgenstein. Nesse sentido, julgamos ser bem distinta em sua obra a utilização do octaedro na representação de interdições, no caso, basicamente de incompatibilidades amplas em fevereiro de 1929 (quando o octaedro cumpre papel semelhante ao da introdução de racionais nas elementares) e de incompatibilidades restritas em 1930 e principalmente em 1950, quando a utilização implícita do "mesmo" modelo continua a apresentar a margem de liberdade relativa a aplicações específicas de palavras para cores.

Segundo julgamos, sendo um sistema de coordenadas para a localização de pontos no espaço cromático, o octaedro não serve em 1929, por exemplo, para indicar a diferença radical entre uma cor não poder ser amarela e vermelha e não poder ser amarela e azul - combinações que, por mistura de pigmentos, nos remetem, sem distinção lógica, ao laranja e ao verde. A nosso ver, essa é uma distinção lógico-gramatical relevante, por meio da qual podemos registrar a diferença entre o objetivo logo abandonado de expressão exata dos fenômenos e a posterior apresentação de proposições gramaticais nas Anotações sobre as Cores, ao tempo que, mais uma vez, faremos notar a diferença entre incompatibilidades amplas e restritas. De todo modo, parece-nos claro que modelo algum pode comportar por si uma teoria, sobretudo quando não se procura a expressão de relações externas. Por outro lado, por óbvio, importa dizer: modelos podem ser mais ou menos adequados, exigir mais ou menos esforço para expressar relações internas. É preciso reconhecer, então, como uma razão para sua preferência, que o octaedro mostra bem exatamente o que Wittgenstein pretendera enfatizar, ajudando-o decerto no deslocamento de sua reflexão para as incompatibilidades restritas.

\footnotetext{
* Professor do Departamento de Filosofia da UFBA, desenvolvendo pesquisa com bolsa do CNPq e apoio da FAPESB.

1 Indicamos os manuscritos (MS) em conformidade com a numeração canônica de von Wright, estando eles disponíveis em WITTGENSTEIN, L. Wittgenstein's Nachlass.

2 Cf. DEGENAAR, M. Molyneux's Problem.

3 Cf. MORENO, A. Wittgenstein: Fenomenologia e Problemas Fenomenológicos.
} 
4 "Jeder Punkt auf der Oberfläche des Oktoeders stellt eine Farbe dar z.B. P ein weißliches Blaurot welches näher dem Rot als dem Blau ist. Eine räumliche Distanz kann durch eine Zahl dargestellt werden. (Dieser Satz handelt nicht von starren Maßstäben.) Er muß sich unmittelbar aus der Struktur des Gesichtsraums ergeben.”(WITTGENSTEIN, MS 105, p. 98 e p. 100.)

${ }^{5}$ WITTGENSTEIN, L. Anotações sobre as Cores, I, $\$ 21$.

6 "Aber das ist auch nicht einwandfrei ausgedrückt, denn dem Farbenraum muß ein grammatischer Raum entsprechen. Und einzelne Wörter etwa „rot”, „gelb” etc. geben keinen Raum. Der Farbenraum wird z.B. beiläufig dargestellt durch das Oktaeder mit den reinen Farben an den Eckpunkten. Und diese Darstellung ist eine grammatische keine psychologische. Zu sagen daß unter den und den Umständen - etwa - ein rotes Nachbild sichtbar wird ist dagegen Psychologie (das kann sein, oder auch nicht, das andere ist a priori. Das eine kann durch Experimente festgestellt werden, das andere nicht)." Cf. WITTGENSTEIN, MS 107, pp. 278-279.

7 Cf. WITTGENSTEIN, MS 107, p. 282.

8 Cf.WITTGENSTEIN, MS 108, p. 76.

9 "Stellt man die Farben durch einen Doppelkegel dar statt eines Oktaeders so gibt es auf dem Farbenkreis nur ein zwischen und Rot erscheint auf ihm in dem selben Sinne zwischen Purpur und Orange in welchem Purpur zwischen Blau und Rot liegt. Und wenn das wirklich alles ist was man sagen kann dann genügt die Darstellung durch den Doppelkegel oder mindestens die durch eine doppelte 8-seitige Pyramide. Nun scheint es merkwürdigerweise von vornherein klar zu sein daß man nicht in dem selben Sinne sagen kann Rot habe einen orangen Stich wie Orange hat einen rötlichen Stich. Das heißt es scheint klar zu sein daß die Ausdrücke ,, [x besteht aus $\mathrm{x}$ und $\mathrm{y} \mid \mathrm{x}$ ist ein Gemisch von $\mathrm{x}$ und $\mathrm{y}]$ ” und ,x ist das gemeinsame Bestandteil von $\mathrm{x}$ und $\mathrm{y}$ " hier nicht vertauschbar sind. Wären sie vertauschbar so genügt die Relation „zwischen” zur Darstellung.” (WITTGENSTEIN, MS 108, p. 76).

${ }^{10}$ A edição de Rhees do TS 209 erra em questão que nada tem de irrelevante, como chegamos a comentar em nosso livro A Gramática das Cores em Wittgenstein, p. 197. Importa registrar que a edição brasileira das Observações Filosóficas (Editora Loyola, p. 228) reproduz o mesmo erro.

11 Como afirma no MS 136, p. 28b, "Die Wasserscheide im Farbenkreis".

12 Cf.WITTGENSTEIN, MS 137, p. 6a e seguintes.

13 Cf. WiTtGenSTEIN, MS 108, p. 89.

14 Cf.WITTGENSTEIN, MS 122, p. 129v.

\section{Referências bibliográficas}

DEGENAAR, M. 1996. Molyneux's Problem: Three Centuries of Discussion on the Perception of Forms. Dordrecht: Kluwer Academic Publishers. 
MORENO, A. 1995. Wittgenstein: Fenomenologia e Problemas

Fenomenológicos. In: Manuscrito, Campinas Unicamp, V. XVIII No 2 , pp. 199-225.

SALLES, J. C. 2002. A Gramática das Cores em Wittgenstein. Campinas: CLE-UNICAMP.

WITTGENSTEIN, L. 1973. Some Remarks on Logical Form. In:

COPI, I.; BEARD, R. Essays on Wittgenstein's Tractatus. New York:

Hafner Press, pp. 31-37.

2000. Wittgenstein's Nachlass. Oxford: Oxford University Press. 2011. Anotações sobre as Cores. Campinas: Editora Unicamp. 